\title{
ONREL
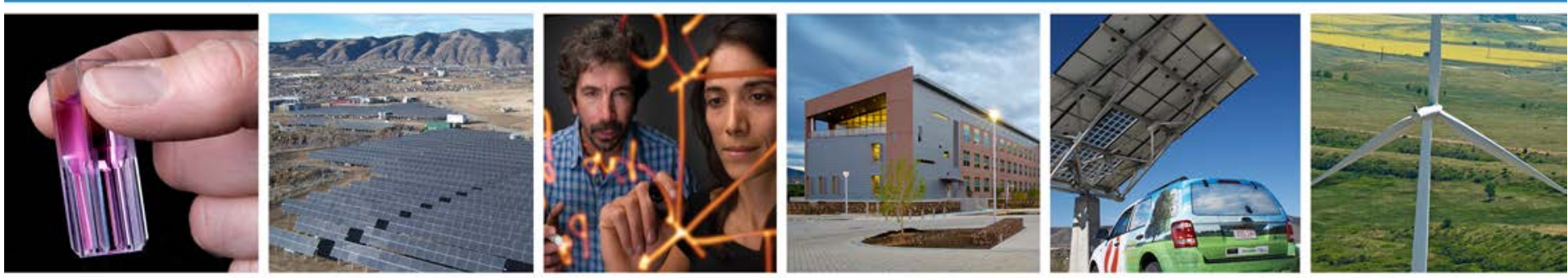

\section{The Potential Role of Concentrating Solar Power in Enabling High Renewables Scenarios in the United States}

Paul Denholm, Maureen Hand, Trieu Mai, Robert Margolis, Greg Brinkman, Easan Drury, Matthew Mowers, and Craig Turchi 


\section{The Potential Role of}

Concentrating Solar Power in Enabling High Renewables Scenarios in the United States

Paul Denholm, Maureen Hand, Trieu Mai, Robert Margolis, Greg Brinkman, Easan Drury, Matthew Mowers, and Craig Turchi

Prepared under Task No. SS12.2721 


\section{NOTICE}

This report was prepared as an account of work sponsored by an agency of the United States government. Neither the United States government nor any agency thereof, nor any of their employees, makes any warranty, express or implied, or assumes any legal liability or responsibility for the accuracy, completeness, or usefulness of any information, apparatus, product, or process disclosed, or represents that its use would not infringe privately owned rights. Reference herein to any specific commercial product, process, or service by trade name, trademark, manufacturer, or otherwise does not necessarily constitute or imply its endorsement, recommendation, or favoring by the United States government or any agency thereof. The views and opinions of authors expressed herein do not necessarily state or reflect those of the United States government or any agency thereof.

Available electronically at http://www.osti.gov/bridge

Available for a processing fee to U.S. Department of Energy and its contractors, in paper, from:

U.S. Department of Energy

Office of Scientific and Technical Information

P.O. Box 62

Oak Ridge, TN 37831-0062

phone: 865.576 .8401

fax: 865.576 .5728

email: mailto:reports@adonis.osti.gov

Available for sale to the public, in paper, from:

U.S. Department of Commerce

National Technical Information Service

5285 Port Royal Road

Springfield, VA 22161

phone: 800.553 .6847

fax: 703.605.6900

email: orders@ntis.fedworld.gov

online ordering: http://www.ntis.gov/help/ordermethods.aspx

Cover Photos: (left to right) PIX 16416, PIX 17423, PIX 16560, PIX 17613, PIX 17436, PIX 17721

Printed on paper containing at least $50 \%$ wastepaper, including $10 \%$ post consumer waste. 


\section{Acknowledgments}

The authors would like to thank Nathan Blair, Adam Green, Mark Mehos, and Robin Newmark for helpful comments and suggestions. 


\section{Executive Summary}

Concentrating solar power (CSP), when deployed with thermal energy storage, provides a dispatchable source of renewable energy. Large-scale deployment of CSP faces a number of challenges - areas with the best direct normal solar resources are often in remote locations, and CSP faces increasing competition from solar photovoltaics (PV), which has fewer siting restrictions and is currently projected to have a lower overall levelized cost of electricity. However, system planners must consider a variety of elements when developing the mix of generators that must reliably meet load. The dispatchability of CSP adds a potentially important complement to variable renewable generation sources such as wind and solar PV.

Two studies sponsored by the U.S. Department of Energy that were completed in 2012 evaluated the potential mix of renewable energy technologies that could serve a large fraction of the U.S. electricity demand and the associated evolution of the U.S. grid to 2050. The SunShot Vision Study evaluated the impact of low-cost solar technologies, while the Renewable Electricity Futures Study analyzed the grid benefits and impacts of providing up to $90 \%$ of the nation's electricity from renewables. A wide range of renewable technologies was evaluated in these studies, including CSP. As a result, these studies provide insights into the potential opportunities and challenges for large-scale deployment of CSP and its benefits as an enabling technology and source of dispatchable energy.

Overall, the studies found a very large range of CSP deployment scenarios, ranging from essentially no new deployment in cases with no cost improvements, to over $100 \mathrm{GW}$ in scenarios with aggressive cost reductions. While some of the scenarios evaluated CSP without storage, the analysis found very limited opportunities for this technology, especially considering projected decreases in PV costs. Alternatively, the use of thermal energy storage, combined with appropriate valuation of its grid flexibility benefits, can result in significant deployment opportunities. These opportunities are dependent on at least three factors: decreased cost, ability to deploy new transmission, and appropriate valuation of CSP flexibility. In all scenarios evaluated in the studies, limited CSP deployment occurs on a pure economic basis at today's costs. However, achieving even partially the goals of the SunShot cost targets can potentially enable significant deployment. This deployment will also depend on the ability to construct new transmission to connect CSP into the existing grid to supply energy to the southwestern United States and California. Very high penetration will require longer-distance transmission to supply a greater fraction of the Western Interconnection and exploit CSP resources that exist in western Texas and on the far western edge of the Eastern Interconnection. Finally, large-scale deployment depends on recognition and valuation of CSP's flexibility and capacity during the system planning process. This valuation is especially important in scenarios where the system becomes highly dependent on variable renewable sources, such as solar PV and wind, and the system requires generators capable of ramping rapidly over a large range of operation. An additional important consideration is the appropriate timing of investment in flexible generation resources, so they are available when less flexible sources of energy are introduced to the grid. Including the value of grid flexibility can produce an overall least-cost energy mix, as opposed to a mix of the lowest-cost energy sources that does not consider the interaction between multiple generation technologies. 


\section{Table of Contents}

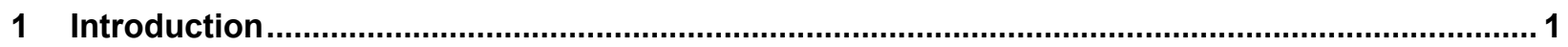

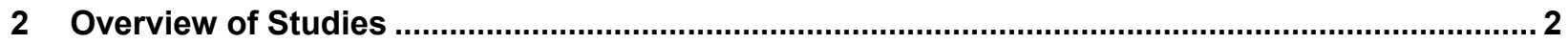

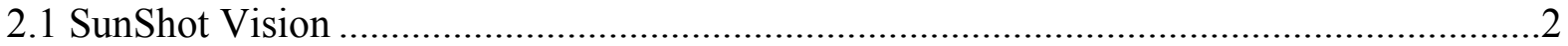

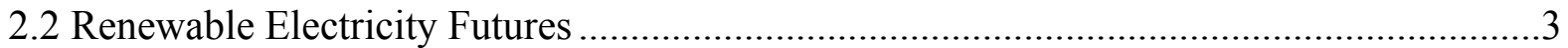

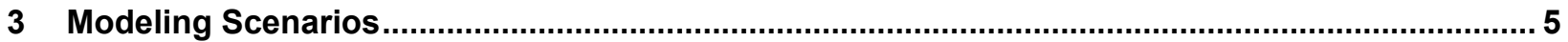

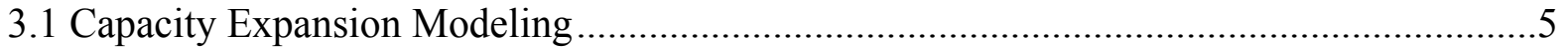

3.2 Implementation of Concentrating Solar Power............................................................6

3.2.1 Concentrating Solar Power Without Storage ................................................ 7

3.2.2 Concentrating Solar Power With Storage ............................................................ 7

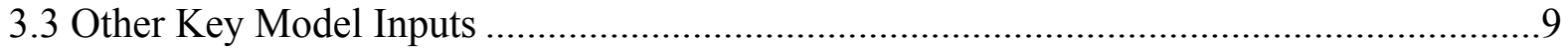

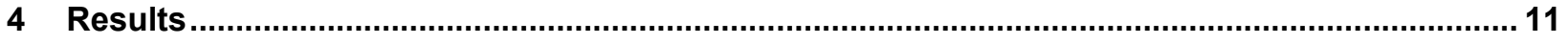

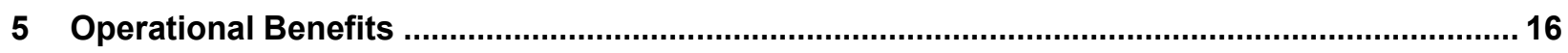

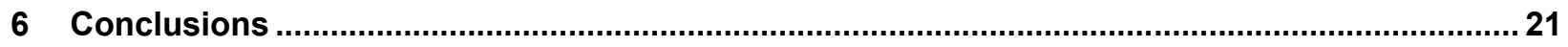

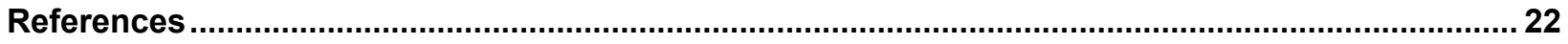




\section{Introduction}

Two studies sponsored by the U.S. Department of Energy (DOE) and completed in 2012 evaluated the potential mix of renewable energy technologies that could serve a large fraction of the U.S. electricity demand and the associated evolution of the U.S. grid to 2050. The SunShot Vision Study (U.S. DOE 2012) evaluated the impact of low-cost solar technologies, while the Renewable Electricity Futures Study (RE Futures) (NREL 2012) analyzed the grid benefits and impacts of providing up to $90 \%$ of the nation's electricity from renewables.

The studies evaluated a number of technologies and explored many of the opportunities and challenges associated with incorporating very large amounts of variable generation renewable sources into the grid. They can also be used to gain insights into the potential role of concentrating solar power (CSP) as a source of dispatchable renewable energy.

This work describes the analysis of CSP in these studies and the potential role of CSP in a future energy mix. Section 2 provides an overview of the two studies, including overall goals and modeled scenarios. Section 3 details the modeling tools used for the studies and the implementation of CSP in the analysis. Section 4 provides the range of CSP deployments in the various scenarios studied, as well as key drivers behind CSP deployment. Overall the studies found a range of opportunities for CSP deployment, largely dependent on reduced technology costs, the ability to construct new transmission, and appropriate valuation of CSP capacity and flexibility, especially in scenarios where the system becomes highly dependent on variable renewable sources such as solar photovoltaics (PV) and wind. 


\section{Overview of Studies}

Both the SunShot Vision and RE Futures studies explored impacts and benefits of large-scale renewable deployment in the United States to 2050. ${ }^{1}$ They explored issues such as overall system cost, impact on electricity prices, changes in carbon emissions and other environmental impacts, job creation, and grid impacts. They both used the same U.S. electric-sector capacity expansion model and evaluated a subset of the scenarios with a more detailed grid simulation tool. Both included a large set of conventional and renewable technologies. However, there are a number of key differences in their objectives, and ultimately their treatment, of CSP. The study objectives are described in greater detail below.

\subsection{SunShot Vision}

The SunShot Vision study was designed to examine the impacts and benefits of achieving significant cost reductions in solar technologies. The SunShot Vision study used the National Renewable Energy Laboratory's (NREL) Regional Energy Deployment System (ReEDS) (Short et al. 2011) and Solar Deployment System (SolarDS) (Denholm et al. 2009) models to develop and evaluate a reference scenario, assuming moderate solar energy price reductions, and the SunShot scenario, where the cost of solar energy is reduced by about $75 \%$ from 2010 to 2020 , along with several additional sensitivity scenarios. In all scenarios, the models were used to develop a least-cost geographical deployment of solar technologies and other generating technologies, including conventional generators such as coal and natural gas, and other renewable generators such as wind. Within the modeling framework, each generation technology competed on a purely economic basis, considering a range of technical and economic performance characteristics described in Section 3. Each modeled scenario produced the installed capacity mix of generator types, annual energy production, and factors, such as total life cycle costs, annual costs, emissions, and other performance indicators. Specific goals of the SunShot Vision study included determining the potential economic market penetration of solar assuming substantially reduced costs. For the SunShot scenario, solar technology installed system prices were assumed to reach the SunShot Initiative's targets by 2020: $\$ 1.00 / \mathrm{W}$ for utility-scale PV systems, $\$ 1.25 / \mathrm{W}$ for commercial rooftop PV, $\$ 1.50 / \mathrm{W}$ for residential rooftop PV, and $\$ 3.60 / \mathrm{W}$ for CSP systems with up to 14 hours of thermal energy storage (TES) capacity. ${ }^{2}$ Four additional sensitivity scenarios were also evaluated, two with less aggressive solar cost reductions, and two examining the impact of cost reductions of other technologies. Major assumptions are described in more detail in Section 3. A key element behind all scenarios was that solar technologies compete on a purely economic and unsubsidized basis - the scenarios assume the federal investment tax credit (ITC) and production tax credit (PTC) run through their currently established expiration dates - end of $2016^{3}$ and 2012, respectively - and that existing supports for conventional technologies that are embedded in the tax code or through other provisions continue indefinitely. Solar growth based on non-cost factors [e.g., greenhouse gas (GHG) reduction, fuel price stability, and energy security benefits] was not considered in the analysis.

\footnotetext{
${ }^{1}$ All results in this report refer to the contiguous United States (excluding Alaska and Hawaii).

${ }^{2}$ Note that throughout this report all " $\$ / W$ " units refer to 2010 U.S. dollars per peak watt-direct current (DC) for PV and 2010 U.S. dollars per watt-alternating current (AC) for CSP, unless otherwise specified.

${ }^{3}$ The ITC drops to $10 \%$ in 2016 , and while it currently has no expiration date, the studies make the more conservative assumption that it expires completely in 2030.
} 
An additional aspect of the SunShot Vision study was to evaluate grid impacts through the use of a grid simulation model. Results from the capacity expansion model were used as inputs to a commercial production cost model which was then used to evaluate the hourly balance of energy supply and demand. GridView was also used to evaluate changes to grid operation required due to increased use of variable solar generation.

\subsection{Renewable Electricity Futures}

The RE Futures study was designed as an initial investigation of the extent to which renewable energy supply can meet the electricity demands of the contiguous United States. The analysis examined the implications and challenges of renewable electricity generation levels-from 30\% up to $90 \%$, with a focus on $80 \%$, of all U.S. electricity generation from renewable technologies - in 2050.

As with the SunShot Vision study, RE Futures used the ReEDS and SolarDS models to develop a set of reference and high renewable energy scenarios. The biggest single difference between the studies was the basis on which they deployed renewable energy. The SunShot Vision study developed generation mixes solely on an economic least-cost basis, though with an aggressive cost-reduction target for solar technologies. RE Futures set targets for renewable penetrations for the year 2050 (from 30\% to $90 \%$ of all demand) and evaluated the resulting least-cost geographical deployment of all conventional and renewable generating technologies. Renewable sources essentially competed against each other for market share within this overall renewable requirement. RE Futures also evaluated many more scenarios considering different cost reduction trajectories and constraints on various technology deployments, although RE Futures did not consider any scenarios with cost reductions for solar technologies as aggressive as in the SunShot Vision study. RE Futures explored a similar set of topics as the SunShot Vision study, such as resource availability, impact on system costs, environmental impacts and benefits, and basic grid operation.

Compared to the SunShot Vision study, where 6 scenarios were evaluated (base case, SunShot case, and 4 sensitivities), a total of 27 scenarios were evaluated in RE Futures ( 5 base cases and 22 renewable cases). As with the SunShot Vision study, the base cases had no renewable deployment requirements. Differences between the base cases were based on assumptions regarding fossil fuel prices and demand growth. The "primary" base case evaluated in RE Futures is the low-demand baseline scenario where there is little growth in demand (due to largescale deployment of energy efficiency technologies), resulting in a demand in 2050 of 3,900 TWh (compared to 3,600 TWh in 2008). A high-demand reference scenario was also established, where the end-use electricity demand in 2050 is $5,100 \mathrm{TWh}$, or $30 \%$ higher than in the low-demand scenarios. This high-demand trajectory is also identical to the demand trajectory used in the SunShot scenario.

The renewable cases focused on different levels of required renewable penetration (from $30 \%$ to $90 \%$ by 2050), as well as a variety of assumptions regarding technology cost and performance improvements.

The focus of RE Futures was to evaluate the $80 \%$ scenarios. It included three price trajectory scenarios: the relatively high-price incremental technology improvement scenario (RE-ITI), the mid-range-price evolutionary technology improvement scenario (RE-ETI), and the no- 
technology improvement scenario (RE-NTI) (where the current performance of each renewable technology is maintained at 2010 levels. These trajectories are described in more detail in Section 3. These cases were based on the low-demand growth trajectory. In addition, the study analyzed three additional $80 \%$ scenarios (using the RE-ITI price trajectory) designed to explore technical sensitivities by varying one set of assumptions at a time, including:

1. The constrained transmission scenario places additional constraints on the construction of new transmission.

2. The constrained flexibility scenario increases the challenges of integrating variable resources by increasing their reserve requirements and decreasing conventional generator flexibility.

3. The constrained resources scenario reduces the availability of renewable resources.

The number and diversity of scenarios enabled an assessment of multiple pathways that significantly depend on highly uncertain future technological, institutional, and market choices. Section 3 describes the modeling framework in more detail and the implementation of CSP in the various scenarios, including cost and performance assumptions. As with SunShot, several cases (the $80 \%$ RE-ITI, 80\% RE-ETI, baseline, and constrained transmission scenarios) were further evaluated using a grid simulation tool. 


\section{Modeling Scenarios}

\subsection{Capacity Expansion Modeling}

The primary analytic tool used for both studies was the ReEDS model. ReEDS is a generation and transmission capacity expansion model of the electricity system of the contiguous United States. ReEDS includes a highly discretized regional structure and detailed statistical treatment of the impact of variability of wind and solar resources on capacity planning, operating reserve requirements, and curtailment levels. The ReEDS model selects the mix of generators that minimizes overall life cycle electric system cost subject to a large number of constraints. The major constraints include meeting electricity demand and reserve requirements within specific regions, regional resource supply limitations, state and federal policies, technology growth constraints, and transmission constraints. In satisfying these constraints in a least-cost manner, the ReEDS optimization routine chooses from a broad portfolio of conventional generation, renewable generation, and storage technologies, as well as demand-side management, and simultaneously optimizes technology capacity expansion, generator dispatch, and transmission capacity expansion. The model does not choose technologies simply based on their levelized cost of energy - ReEDS co-optimizes energy, capacity, and ancillary service requirements along with the temporal characteristics of variable generators among other factors to produce an overall mix of generators that minimizes the system cost. Transmission capacity expansion is an important component of evaluating the least-cost mix of new generation, evaluating the tradeoff between resources of varying quality and the impact of sharing resources over larger regions. In the optimization, ReEDS considers the present value cost of its investment and operation decisions over an assumed financial lifetime (20 years for the present study). This cost minimization routine is applied for each 2-year period through 2050.

ReEDS represents the contiguous United States using $356 \mathrm{CSP} /$ wind resource regions and 134 power control areas. This level of geographic detail enables the model to account for geospatial differences in resource quality, transmission needs, electrical (grid-related) boundaries, and political boundaries. ReEDS dispatches generation within 17 different time slices, including 4 time slices for each season representing morning, afternoon, evening, and nighttime, with an additional summer-peak time slice. This level of temporal detail-though not as sophisticated as an hourly chronological dispatch model - enables ReEDS to consider seasonal and diurnal changes in demand and resource availability. Because there are still significant demand and resource variations that can occur within each of these time slices, ReEDS utilizes statistical calculations derived from hourly data to estimate the capacity value and curtailment of variable wind and solar resources. ReEDs also considers the correlations of hourly output profiles between resources in different locations and additional operating reserve requirements from variable generation technologies. These measures are used to help ensure that ReEDS scenarios are as geographically and temporally detailed as computational constraints allow, while also being consistent with an electricity system that is able to maintain an overall balance between supply and demand.

Major outputs of ReEDS are the regional deployment and dispatch of generator technologies, regional transmission capacity expansion, and power transfers between regions in the 17 different time slices. ReEDS also calculates the impacts of each scenario, including the total electric-sector cost, electricity price, fuel use and price, and carbon emissions. 
Additional detail for ReEDS can be found in the ReEDS model documentation (Short et al. 2011). Certain assumptions cited in the model documentation are different than those used in the two studies; these specific details are generally outlined in the study appendices.

Because ReEDS is not designed to account for distributed rooftop PV generation, the penetration of distributed (residential and commercial) PV capacity is exogenously input into ReEDS from the SolarDS model. SolarDS evaluates potential market penetration of commercial and residential rooftop PV, based on regional electricity prices, financial incentives, regional solar resource quality, and rooftop availability.

\subsection{Implementation of Concentrating Solar Power}

CSP uses mirrors or lenses to concentrate sunlight and produce intense heat, which is used to produce electricity via a thermal energy conversion process similar to those used in conventional power plants. ReEDS models CSP plants both with and without TES. Modeling of CSP performance begins with the establishment of five resource classes based on direct-normal irradiance (DNI), as illustrated in Figure 1.

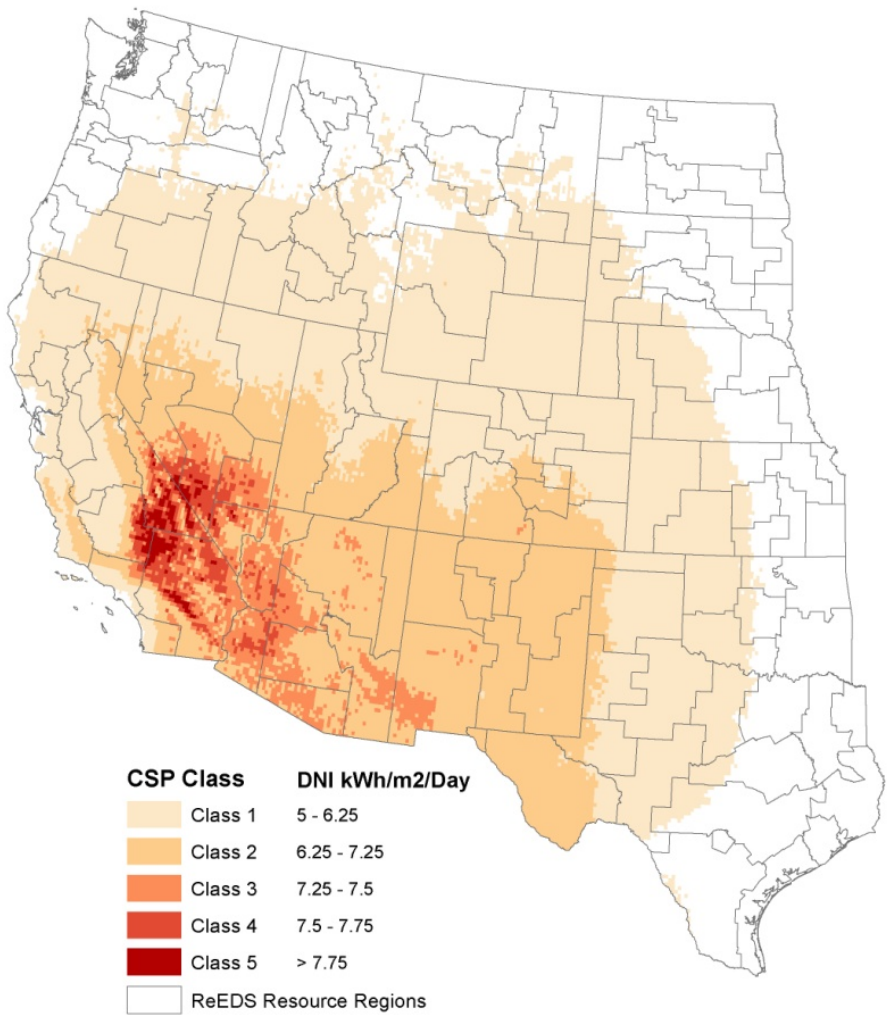

Figure 1. CSP resource in the United States (U.S. DOE 2012)

Note: A small amount of class 1 resource in Florida is not shown.

The resource data is translated into a typical DNI year (TDY) hourly resource dataset for representative sites of each CSP/wind resource region. The TDY weather files were processed through the CSP modules of the System Advisor Model (SAM) (NREL 2010) to generate 
performance characteristics for two types of CSP systems considered in ReEDS - differentiated by their use of storage described below.

\subsubsection{Concentrating Solar Power Without Storage}

The CSP system without TES in ReEDS is represented as a dry-cooled trough plant with a solar multiple of 1.4. Solar multiple is defined as the ratio of the power capacity of the collection field to the capacity of the power block. A solar multiple of 1.0 would provide sufficient thermal energy to operate the power block at full capacity under design point conditions. Hourly profiles were generated using the SAM model, and these profiles were then translated into capacity factor by time slice used by the ReEDS model. These hourly profiles were also used to estimate capacity value. For RE Futures, cost projections were developed by Black \& Veatch (2012). The 2010 assumed cost is $\$ 5,000 / \mathrm{kW}$ and declines over time based on one of three cost trajectories. The RE-NTI assumes no cost decrease. The RE-ITI reflects a partial achievement of the future technical advancements and assumes a decrease to $\$ 3,530 / \mathrm{kW}$ by 2050 . The RE-ETI scenario reflects a more complete achievement of possible future technical advancements, where the cost decreases to $\$ 3,070 / \mathrm{kW}$ in 2020 and then remains constant to 2050 . As noted in the results sections virtually no CSP plants without TES are deployed in any RE Futures scenario. Because the goals of the CSP SunShot program are focused on dispatchable CSP, CSP without TES was not modeled in the SunShot scenario.

\subsubsection{Concentrating Solar Power With Storage}

In ReEDS, CSP systems with TES are represented by three separate components: the field (collectors), storage, and turbine (power block). The model is allowed to choose solar multiples and amounts of storage within boundaries discussed later in this section. Greater solar multiples result in higher capacity factors, and greater amounts of storage allow the systems to be more flexible, although both increase capital costs per kilowatt of installed turbine capacity.

ReEDS considers CSP systems with TES to have at least 6 hours of storage, for which ReEDS assumes full capacity credit valuation (Madaeni et al. 2011).

CSP systems with TES are assumed to be fully dispatchable within the energy limitations imposed by the time-profile of the solar insolation, solar multiple, and hours of thermal storage. Because of this, capacity factors by time slice of CSP with TES are an output of the model, not an input. Instead, the profile of power input from the solar field of the CSP plants are model inputs, based on SAM simulations from the TDY weather files that span the range of solar multiples allowed in ReEDS.

While solar multiple and hours of storage are allowed to be system-specific in ReEDS, the overall design space of the CSP plant configuration is limited to produce acceptable model run times. Specifically, for each solar multiple, there is a minimum amount of storage required to minimize curtailment and to consider only the more likely CSP configurations. The minimum number of hours of storage for any solar multiple is 6 , while for a solar multiple of 2.5 , which is the maximum allowed, a minimum of 11 hours of storage is required.

Table 1 shows average costs for CSP systems with TES in the various scenarios. Both studies also considered fixed operation and maintenance, with ranges between $\$ 50 / \mathrm{kW}$-year and $\$ 75 / \mathrm{kW}$-year (regardless of capacity factor or operation), depending on scenario. 
Table 1. Price Inputs for SunShot and RE Futures Solar Technologies (\$/W) ${ }^{a}$

\begin{tabular}{|c|c|c|c|c|}
\hline \multirow{2}{*}{ Year } & \multirow{2}{*}{ SunShot $^{\mathbf{b}}$} & \multicolumn{3}{|c|}{ RE Futures $^{\mathbf{c}}$} \\
\cline { 3 - 5 } & & RE-NTI & RE-ITI $^{\mathbf{d}}$ & RE-ETI \\
\hline 2010 & 9.2 & 7.1 & 7.1 & 8.2 \\
\hline 2020 & 3.4 & 7.1 & 6.2 & 4.1 \\
\hline 2030 & 3.4 & 7.1 & 5.3 & 2.9 \\
\hline 2040 & 3.4 & 7.1 & 4.7 & 2.9 \\
\hline 2050 & 3.4 & 7.1 & 4.7 & 2.9 \\
\hline
\end{tabular}

${ }^{\text {a }}$ Prices reflect technology capital cost assumptions in 2010 U.S. dollars (\$/W-AC nameplate capacity). ReEDS actually models the field, storage, and power block independently based on restrictions stated previously. For detailed component estimates used, see volume 2 of the RE Futures study.

${ }^{\mathrm{b}}$ Based on $\mathrm{SM}=2.5$ and 11 hours of storage.

${ }^{\mathrm{c}}$ Based on $\mathrm{SM}=2.0$ and 6 hours of storage.

d The RE-ITI price inputs also apply to the RE Futures constrained transmission, constrained flexibility, constrained resources, and high-demand $80 \%$ renewable electricity scenarios.

In addition to performance characteristics and costs, available land area (and corresponding capacity) was also established for each resource class. Figure 2 provides the availability of CSP at each CSP/wind resource region ${ }^{4}$ in the western United States (with a small amount of class 1 CSP available in southern Florida). This resource availability considers land unavailable for development based on a large set of exclusions, such as slope and environmental restrictions. ${ }^{5}$ After removing this excluded land, remaining area for each CSP resource class is converted into gigawatts of available capacity assuming a plant density of $31 \mathrm{MW} / \mathrm{km}^{2}$ for a system with a solar multiple of 2. ${ }^{6}$ Overall, the resource base in the United States for CSP is very large - after exclusions, about 7,500 GW, producing about 17,500 TWh of annual CSP electricity generation (more than four times the current U.S. annual demand) could be sited in seven southwestern states (NREL 2012).

\footnotetext{
${ }^{4}$ Although the resource is quantified at the $356 \mathrm{CSP} /$ wind region level, only CSP without TES is located at this level. CSP with TES is located at the 134 power control area region level.

${ }^{5}$ These exclusion areas are discussed in more detail in the RE Futures and SunShot Vision studies.

${ }^{6}$ Plant density for systems with other solar multiples is assumed to scale inversely with solar multiple. As an example, a CSP system with a solar multiple of 1 would be assumed to have a plant density of $62 \mathrm{MW} / \mathrm{km}^{2}$, or twice that of a system with a solar multiple of 2 .
} 

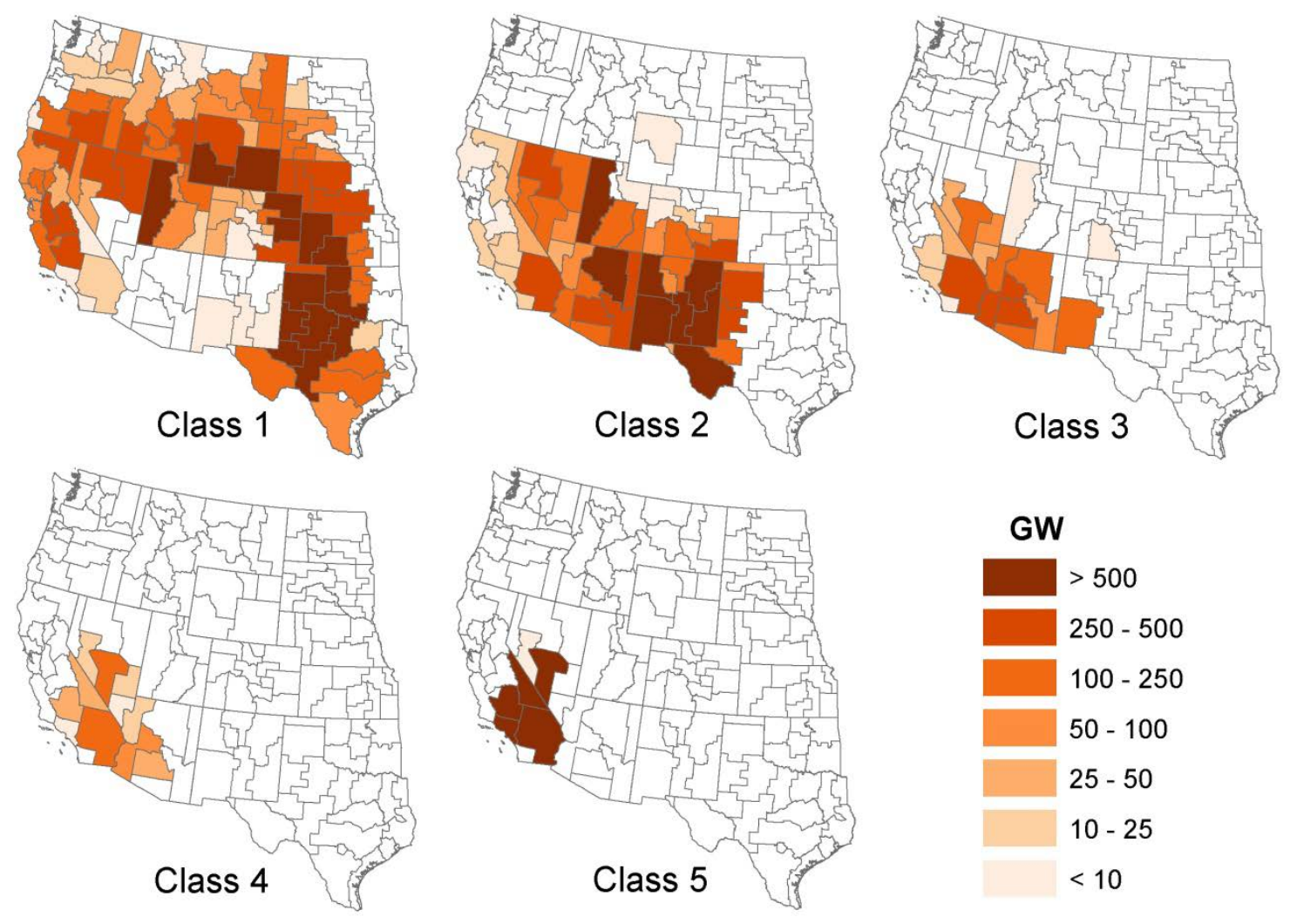

Figure 2. CSP available resource by class (for solar multiples of 2) (U.S. DOE 2012)

CSP plants must be interconnected to the grid, often requiring new transmission. Based on the CSP resource data, a supply curve representing the cost of connecting individual CSP sites to the existing grid as well as to local demand centers was developed based on a geographic information system database of the resource, existing grid, ${ }^{7}$ and loads. Additional transmission may be built by ReEDS to enable CSP to provide energy over long distances, even across interconnections, when it is cost competitive compared to other options to provide energy, capacity, and flexibility. In addition to the transmission costs associated with the supply curves, a $\$ 120 / \mathrm{kW}$ fee for connection to the grid is applied to new CSP plants in ReEDS.

\subsection{Other Key Model Inputs}

Both studies use the same modeling framework, with a very large set of common input parameters and assumptions, documented in the study reports. A key difference between the two studies includes the difference in load growth noted previously. Other significant differences are related to the assumed cost trajectories for a number of generation technologies.

For conventional and non-solar renewable energy technologies, the SunShot scenario and the RE Futures RE-ITI scenario both assume price reductions as projected by Black \& Veatch (2012). In the RE Futures RE-ETI scenario, greater renewable technology price reductions are assumed, while the RE-NTI scenario assumes no renewable technology price reductions.

\footnotetext{
${ }^{7}$ Ten percent of the total carrying capacity of each transmission line was assumed to be available for CSP spur lines.
} 
Renewable technologies considered in both studies include wind (onshore and near-offshore), geothermal, and biopower (both dedicated and co-fired with coal). RE Futures also considered new hydro power. Neither study considered technologies currently under development but not yet deployed at scale, such as enhanced geothermal systems and ocean energy technologies.

For fossil fuel generation technologies, both studies include gas combined-cycle, gas combustion turbine, and pulverized coal; SunShot also allowed new coal gasification combined cycle plants. Both studies use natural gas and coal fuel price supply curves from Energy Information Administration's Annual Energy Outlook 2010 projections through 2035 (EIA 2010). In RE Futures, these projections remain constant after 2035. In SunShot, natural gas and coal fuel supply curves are extrapolated after 2035 based on the average price increases between 2015 and 2035. There are no constraints on carbon emissions nor costs associated with carbon emissions; however, there is a carbon risk premium on new coal plants $(6 \%$ in SunShot and 3\% in RE Futures). Generator technical performance, such as plant heat rate, outage rate, and ramping capabilities, are the same between studies and described in the report appendices.

Both studies considered deployment of several storage technologies and interruptible load. RE Futures assumed substantial adoption of electric and plug-in hybrid-electric vehicles, with some flexibility of when charging occurs.

Grid standards and requirements (such as planning reserve and operating reserve requirements) are generally the same in both studies. 


\section{Results}

There is a significant range in CSP deployment in the various scenarios models, driven by the different input assumptions, cost trajectories, and other factors. As noted previously, deployment in the SunShot scenarios are based on purely economic deployment without incentives, while RE Futures cases have specific renewable requirements. There are a large number of drivers behind both the evolution of deployment of CSP and the total deployment in 2050. Even in the aggressive SunShot case, deployment of CSP is low in the near term. This is illustrated in Figure 3, which shows the trajectory of CSP growth in several scenarios. (In this and all other figures, "REF" refers to scenarios from the RE Futures studies). It includes the SunShot reference case, where there is virtually no growth in CSP; the RE-ITI, which shows modest growth; and two high growth scenarios, the SunShot and RE-ETI scenarios.

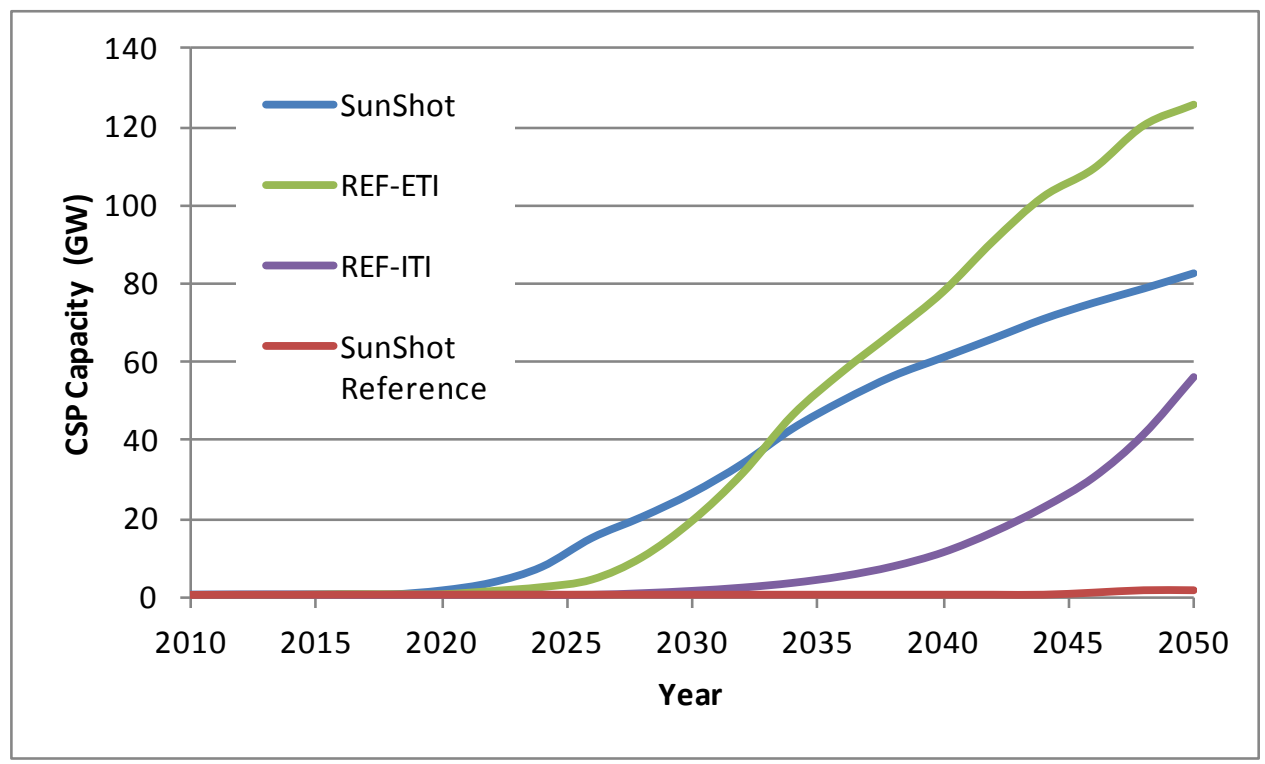

Figure 3. CSP capacity growth for four scenarios

A primary driver behind the limited near-term growth is the relatively high delivered cost of energy from CSP, as well as limited value of its flexibility at low penetrations of variable generation. At low penetrations of wind and PV, both sources are incorporated into the existing grid mix with limited additional need for system flexibility - the existing mix of generators is largely able to accommodate the additional variability and uncertainty. At low penetration, the energy value of wind and PV is relatively high, replacing higher-cost fuels with limited curtailment (Mills and Wiser 2012; Denholm et al. 2008). PV also has relatively high capacity value given its coincidence with demand patterns. Under these conditions, the firm capacity and dispatchability of CSP is less valuable, and it must compete essentially on a pure cost-of-energy basis.

As penetration of wind and solar PV increases, grid flexibility requirements also increase. Wind and PV begin to displace less valuable energy sources, and curtailment of these sources may increase (Denholm and Margolis 2007). Capacity value falls, particularly for PV where the demand peak is shifted to the early evening. Under these conditions, the dispatchability of CSP becomes more important, as the grid needs generation sources that can meet demand during the 
late afternoon and evening (Denholm and Mehos 2011). In both SunShot Vision and RE Futures, this occurs beyond the 2020 timeframe and coincides with projected decreasing costs of CSP technologies. The combination of flexibility requirements and lower-cost CSP corresponds to the significant increase in growth beginning in about 2025 for SunShot, and somewhat later in various RE Futures scenarios. A previous analysis of CSP deployment using the ReEDS model found similar results (Blair 2007).

Given CSP cost reductions, the flexibility provided by CSP can lead to significant market penetration in the longer term. Figures 4 and 5 compare the installed capacity and overall contribution of CSP in the SunShot and RE Futures scenarios in 2050. In the reference scenarios, very little CSP (or other renewable technologies) are deployed due to little or no cost reductions in CSP technologies. However, several of the SunShot and RE Futures scenarios show significant deployment of CSP. In the Sunshot scenario, about $83 \mathrm{GW}$ of CSP is installed by 2050 , contributing about $8 \%$ of total U.S. electric demand. The most directly comparable RE Futures case is the high-demand scenario. This scenario, based on the RE-ITI cost trajectory results in a CSP deployment of about $73 \mathrm{GW}$, providing $6 \%$ of demand. This difference is driven largely by the lower solar technology prices in the SunShot scenarios.

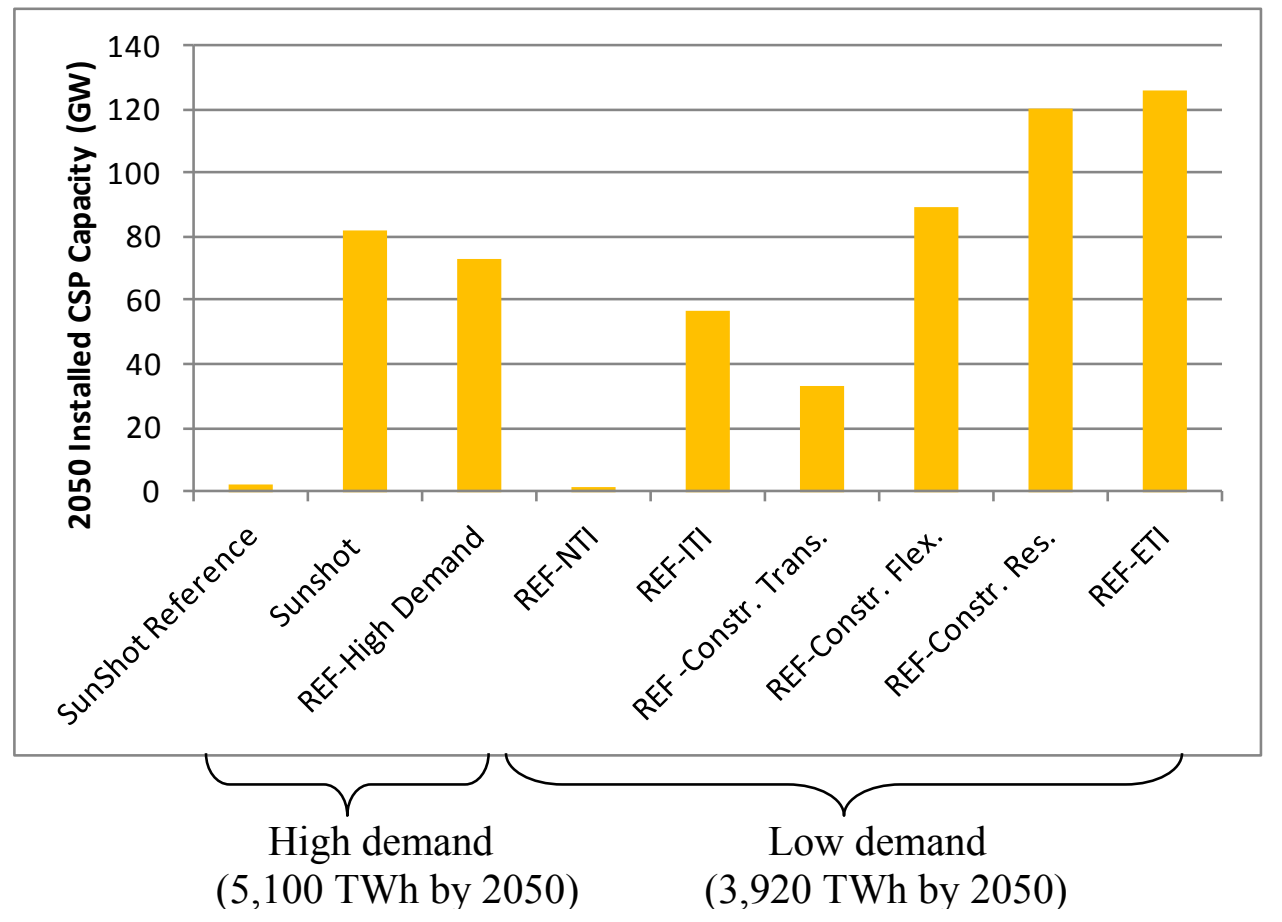

Figure 4. Installed CSP capacity in 2050 under the SunShot scenario and RE Futures $\mathbf{8 0 \%}$ renewable electricity scenarios 


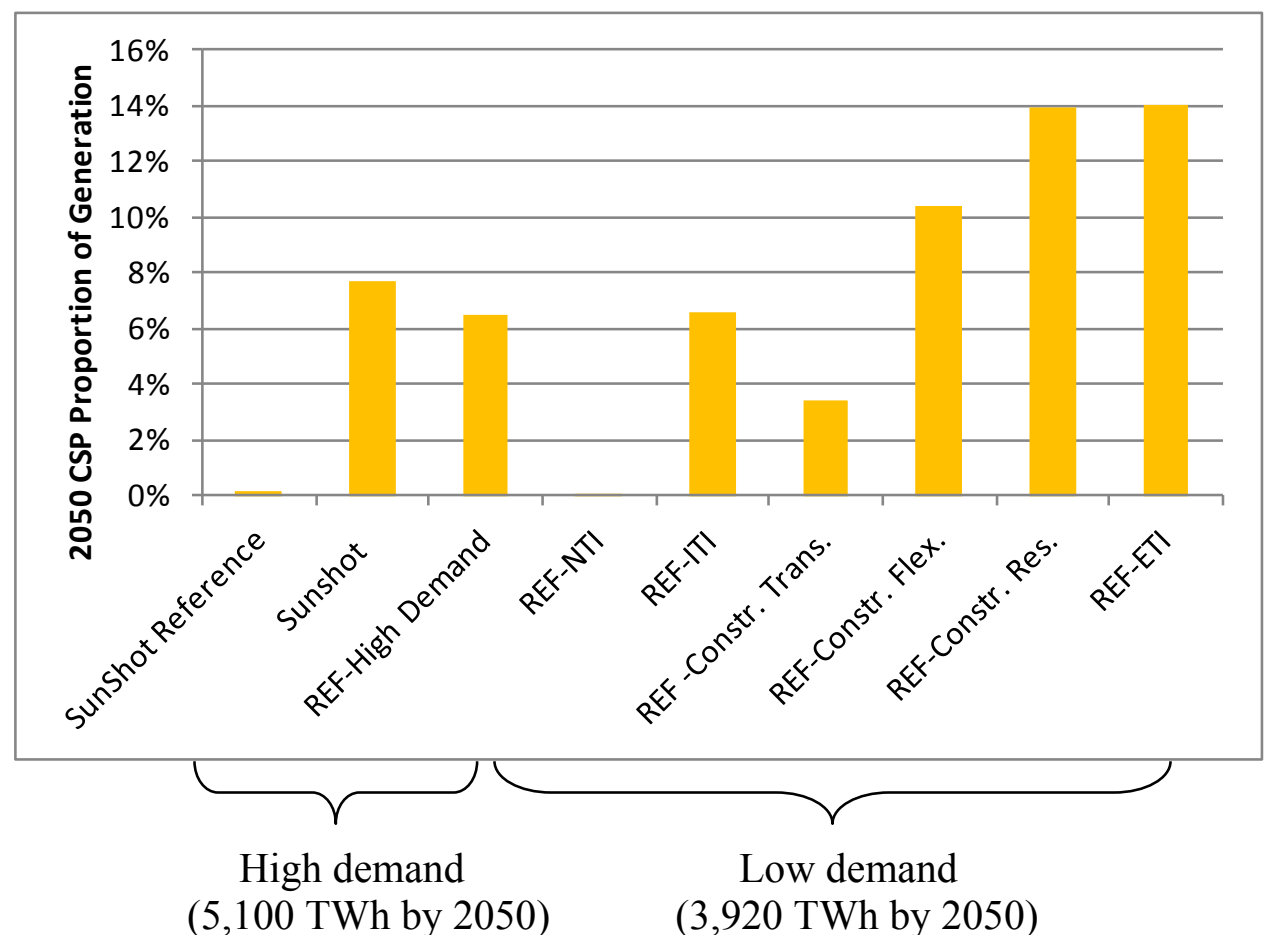

Figure 5. Proportion of electricity generated by CSP technologies in 2050 under the SunShot scenario and RE Futures $\mathbf{8 0 \%}$ renewable electricity scenarios

These results show that large-scale deployment of CSP $(\geq 10 \mathrm{GW})$ is dependent on some combination of substantially reduced costs and the use of its ability to provide grid flexibility. In cases where CSP shows little performance improvement and the grid uses small amounts of variable generation, CSP faces a challenging economic environment, and ReEDS shows relatively little deployment. Overall, the fraction of generation contributed by CSP with storage varies greatly with the different scenarios and actually has the greatest range of contribution of all the technologies evaluated in the RE Futures study. This reflects the sensitivity of CSP to multiple factors. Cost appears to be the most significant driver, showing large growth in CSP under the more aggressive cost reduction cases. The most aggressive cost reduction scenario (RE-ETI) results in $126 \mathrm{GW}$ of CSP, providing 14\% of total national generation. However, CSP deployment showed significant variation in the three sensitivity cases (constrained flexibility, constrained transmission, and constrained resource scenarios) based on the RE-ITI case, which used identical CSP costs. In the RE-ITI case, a total of 56 GW of CSP is deployed in 2050, providing about $7 \%$ of total generation. In the constrained flexibility case, where reserve requirements from PV and wind are increased while reducing conventional generator flexibility, the value of dispatchable CSP is greatly increased, and its overall penetration increases to $89 \mathrm{GW}$ and $10 \%$ of generation. The constrained resource case also greatly increased CSP penetration, resulting in penetration levels close to the lower-cost ETI case. Alternatively, constraining the ability to build new transmission substantially reduced the ultimate contribution from CSP, showing the need for both new local transmission and, potentially, long-distance transmission to enable CSP to serve load beyond local load centers.

The need for new transmission and the remote locations of CSP resources are key challenges for large-scale deployment of CSP. One important issue is the limited demand for electricity in states with good DNI resources. While states like California are large, the overall demand in the 
six states with excellent DNI resources (with at least some class 3 and above) is only about $12 \%$ of total U.S. demand in 2010 (EIA 2011). This requires increasing the use of CSP in regions with lower-quality resources or building long-distance transmission to send CSP generation to surrounding regions. This will likely require building greater connection between the Western and Eastern Interconnections as the Western Interconnection as a whole represents only about $18 \%$ of total U.S. demand. Furthermore, within the Western Interconnection, CSP obviously competes with high-quality PV resources, but it also competes with good-quality wind resources, the nation's highest-quality geothermal resources, and existing hydro. These issues resulted in very high penetrations of renewable energy in the Western Interconnection-in SunShot Vision, about $78 \%$ of demand is derived from renewable sources in 2050, while in several RE Futures $80 \%$ cases, renewable generation greatly exceeds $100 \%$ of the net demand (including transmission losses) in the West. These cases result in substantial net exports out of the Western Interconnection made available by extensive new transmission, as well as significant renewable curtailment. This is illustrated in Figure 6, showing the contribution of CSP (along with other renewable resources in the Western Interconnection) in 2050.

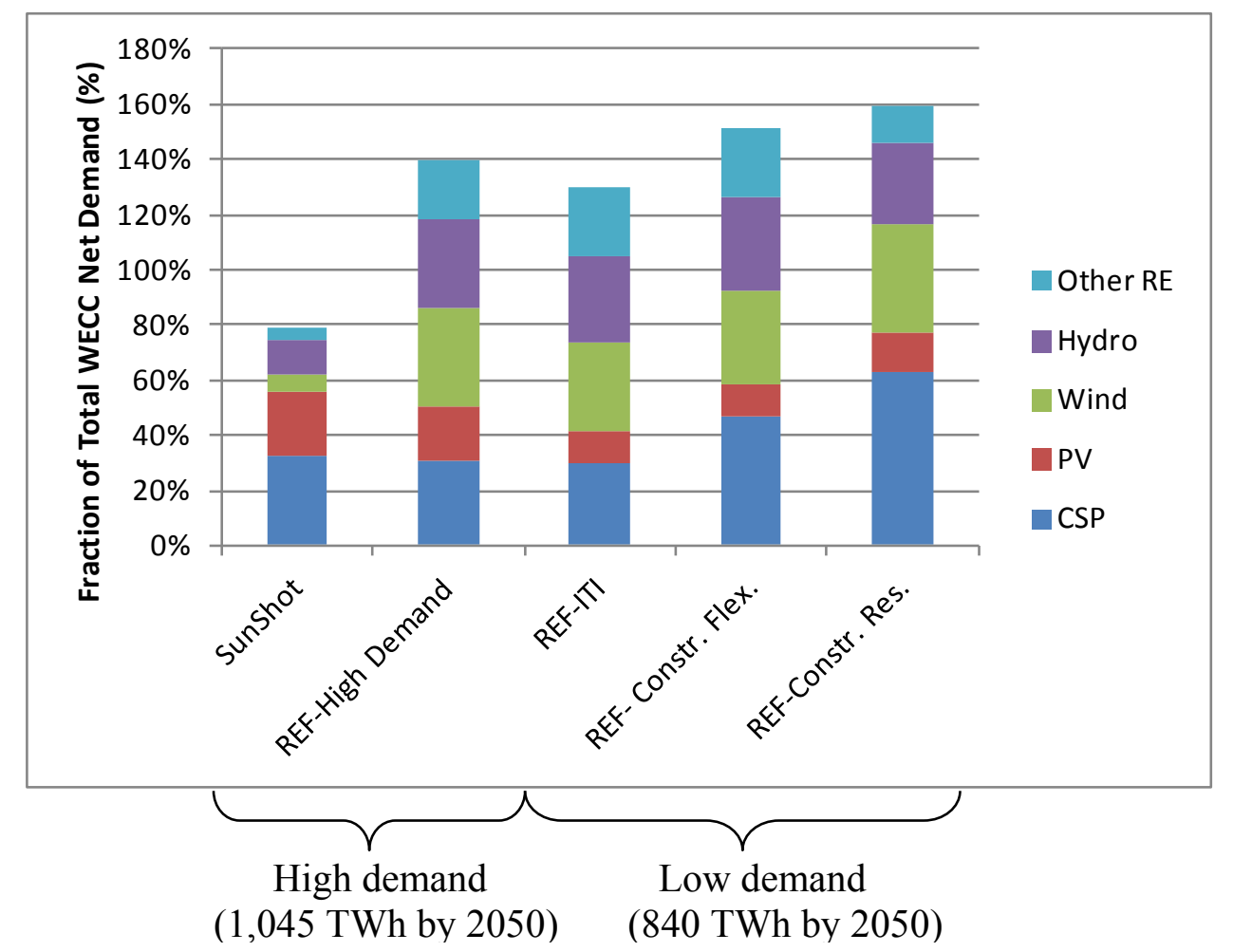

Figure 6. Contribution of renewable resources in the Western Interconnection

As a result of limitations of deploying CSP exclusively in the West, the highest CSP deployment cases developed substantial CSP resources outside the Western Interconnection, as illustrated in Table 2. While in all scenarios most of the development in the East is actually on the far western part of the interconnection, the total available CSP resource in Florida (about 1.6 GW) is constructed in five RE Futures cases and in the SunShot Vision study. The constrained transmission case especially disincentivizes CSP in the Western Interconnection because the cost of new transmission is tripled and the deployment of new transmission across the Interconnections is disallowed, eliminating the possibility of exports from the highest quality 
CSP resource regions. ${ }^{8}$ This also incentivizes somewhat greater CSP development in the Eastern Interconnection and Texas than in the equal-cost RE-ITI case.

Table 2. Distribution of CSP Capacity in 2050

\begin{tabular}{|l|c|c|c|}
\hline & \multicolumn{3}{|c|}{ 2050 Capacity (GW) } \\
\hline Scenario & West & ERCOT $^{\mathbf{a}}$ & East $^{\mathbf{~}}$ \\
\hline SunShot & 66.9 & 7.2 & 8.3 \\
\hline REF-High Demand & 61.9 & 5.4 & 5.8 \\
\hline RE-ITI & 48.7 & 4.1 & 3.7 \\
\hline $\begin{array}{l}\text { REF -Constr. } \\
\text { Transmission }\end{array}$ & 20.4 & 6.0 & 6.3 \\
\hline $\begin{array}{l}\text { REF-Constr. } \\
\text { Flexibility }\end{array}$ & 75.5 & 8.3 & 5.5 \\
\hline $\begin{array}{l}\text { REF-Constr. } \\
\text { Resources }\end{array}$ & 101.7 & 11.3 & 7.1 \\
\hline RE-ETI & 86.9 & 19.2 & 19.7 \\
\hline
\end{tabular}

${ }^{a}$ This includes only the area within the Electricity Reliability Council of Texas (ERCOT) and does not include construction in Texas that occurs both in the Western and Eastern Interconnections.

${ }^{\mathrm{b}}$ Development occurs in the small part of New Mexico in the Eastern Interconnection, the Texas panhandle, Florida, and Oklahoma.

The role of new interconnections for high penetration of CSP can be observed further in the significant transfer capacity built in all scenarios. The SunShot cases developed a total of $18 \mathrm{GW}$ of new connections between the Eastern and Western Interconnections, while the REF cases built even more - up to $63 \mathrm{GW}$. It should be noted that new interconnections are not constructed solely for CSP, and isolating new transmission constructed solely for CSP is not possible because ReEDS co-optimizes transmission construction for all resources, which allows all forms of generation to share transmission where possible. This is discussed further in Section 5, which also provides further analysis of the important role of CSP with TES in providing grid flexibility in high renewable energy scenarios.

\footnotetext{
${ }^{8}$ For complete details of transmission costs see Appendix A, Section 2.4 of the Renewable Electricity Futures Study (NREL 2012).
} 


\section{Operational Benefits}

While ReEDS was the main analysis tool used in the RE Futures and SunShot Vision studies, an additional tool was used to perform analysis of the operational feasibility. Both studies used ABB's GridView production cost model (ABB 2008) to model the hourly operation of the power system and evaluate the ReEDS model's projected capacity mix and identify operational challenges for a subset of the scenarios. In particular, ReEDS and GridView were compared with regard to how they dispatch generation resources, transmit and curtail electricity, and analyze electric-sector fuel use and emissions. CSP with TES was added to the GridView model, along with a number of other modifications to the database, to enable analysis of both SunShot and RE Futures scenarios.

Overall, the GridView simulations confirm the basic hourly operational feasibility of the various scenarios developed in ReEDS. Electricity demand and operating reserves are completely served in all areas during every hour of the year. Electric-sector operating parameters-primarily fuel use and generation mix - are very similar in ReEDS and GridView. In addition, the model confirmed the importance of CSP in providing grid flexibility.

Figure 7 provides an example system dispatch in the Western Interconnection demonstrating the mix of generation sources used to meet load, as well as the significant net exports that occur even during periods of high demand. It also shows significant curtailment of renewable resourceslargely solar generation in the middle of the day; this means that additional non-dispatchable solar (PV or CSP without storage) will largely be curtailed, particularly in high-solar/lowdemand periods in the spring. 


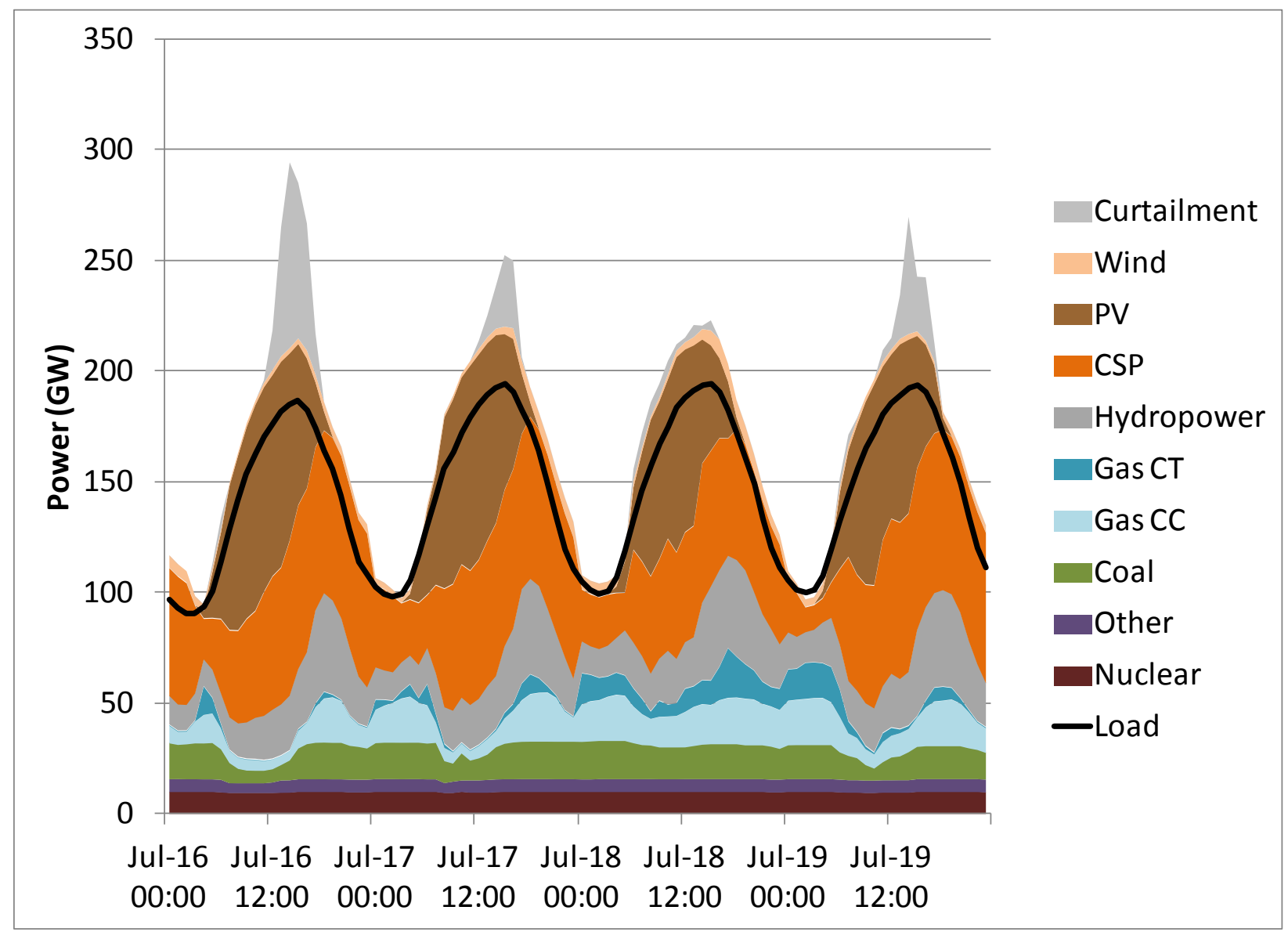

Figure 7. GridView estimated system dispatch for the Western Interconnection for the 2050 SunShot scenario in summer ${ }^{9}$

The dispatch results from GridView demonstrate three important aspects of CSP with TES. First, by shifting mid-day solar to later in the day, TES reduces renewable curtailment and increases the use of renewable energy, compared to cases without TES or other forms of electricity storage. Second, the dispatchability of CSP and its ability to rapidly ramp addresses the increase in variability created by PV and wind. Finally, CSP provides firm system capacity during the evening when the net load (load minus wind and PV generation) peaks. These benefits are illustrated in Figures 8 and 9, which isolate the CSP dispatch, compared to normal load and the net load after non-dispatchable PV and wind are removed. Both figures are for the entire Western Interconnection from the SunShot scenario. Figure 8 illustrates the first two of these benefits during a four-day period in the spring. During these four days, the supply of renewable energy significantly exceeds demand during the middle of the day. Very large amounts of PV create an extremely low net load in the middle of the day, resulting in significant renewable curtailment. About $18 \%$ of potential renewable energy generation is curtailed in these four days, and this would be much higher if CSP generation were not able to shift a significant fraction of its generation to later in the day. The large mid-day generation from PV also creates a large upramp in evening demand, which is largely met by CSP, along with other dispatchable renewable and conventional generation sources.

\footnotetext{
${ }^{9}$ Gas CT $=$ Gas Combustion Turbine, Gas CC $=$ Gas Combined Cycle
} 


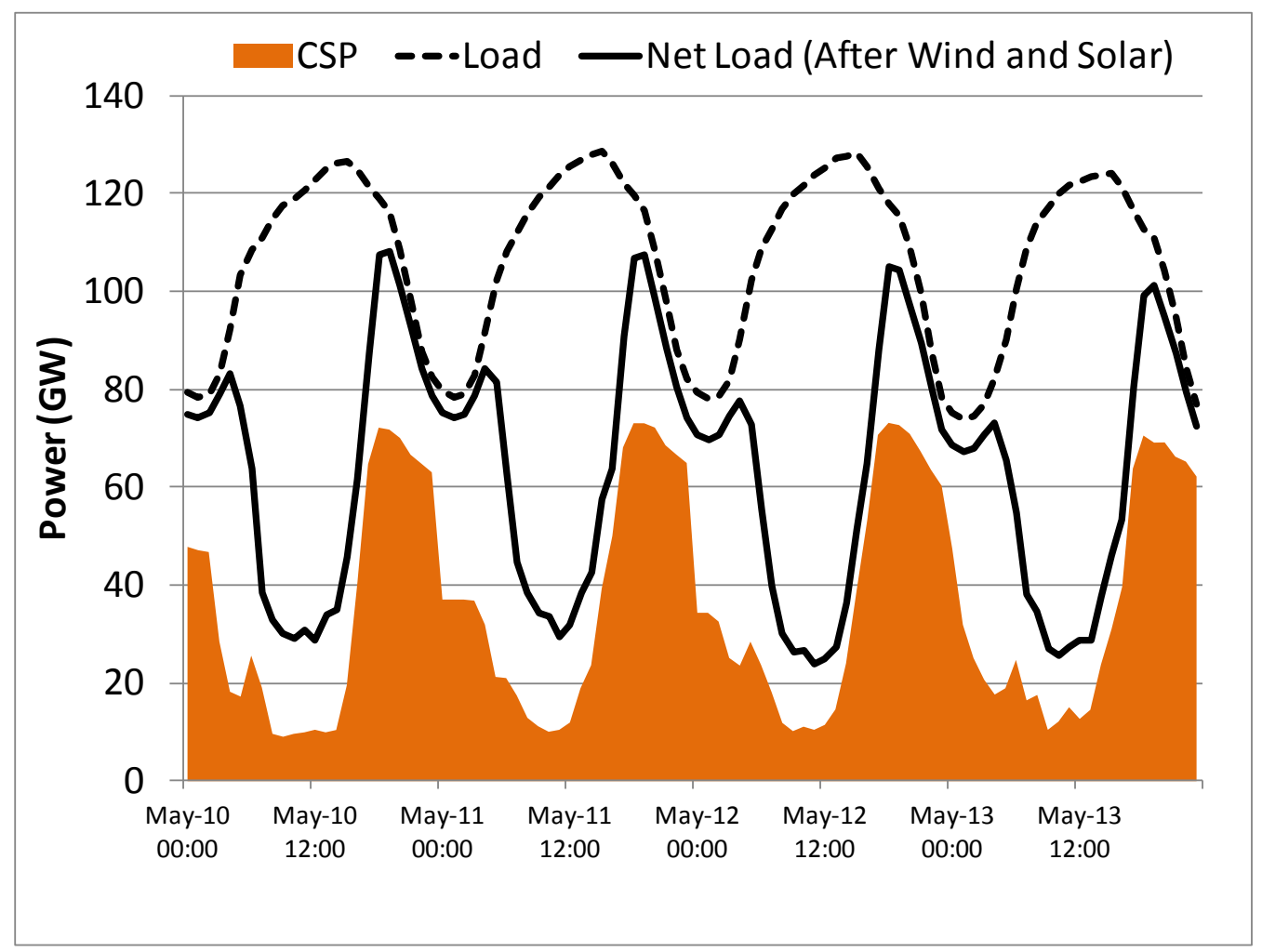

Figure 8. SunShot 2050 CSP dispatch in the Western Interconnection during four spring days

Figure 9 shows the benefits of CSP providing system capacity during periods of net peak demand (variable generation is removed from the normal demand). In these four days the net load peak has been shifted from its normal peak at about 4 p.m. until about 6 p.m., at which point PV output has dropped substantially. CSP with storage is able to generate at its rated capacity on each of these four days to meet the required system planning reserve margin. 


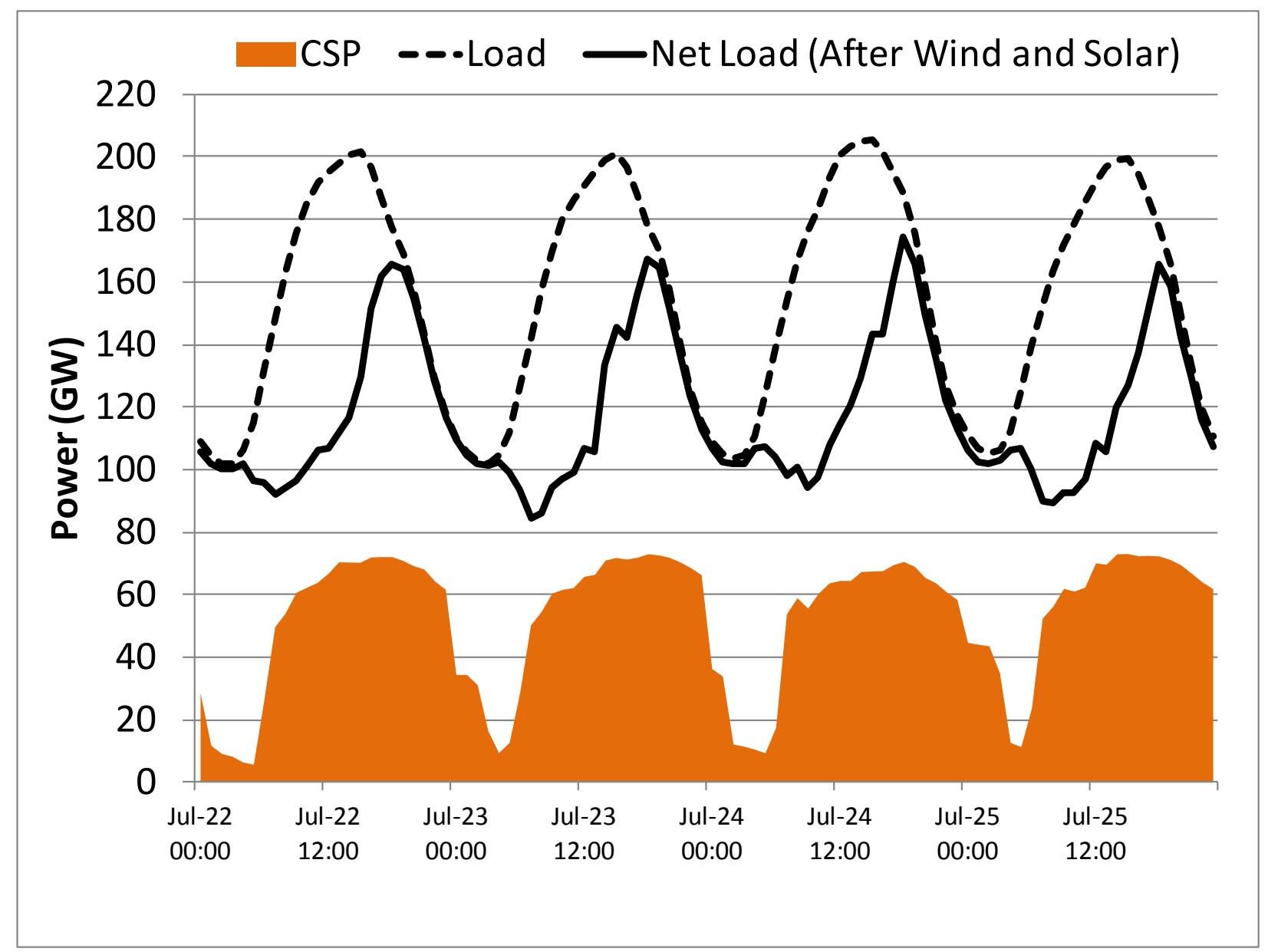

Figure 9. SunShot 2050 CSP dispatch in the Western Interconnection during four summer (peak demand) days

While these results are for SunShot with high penetrations of solar, similar results are observed in the RE Futures cases with significant wind penetrations. Figure 10 provides a case in the Western Interconnection where wind provides about $31 \%$ of annual demand. This four-day period shows a more irregular net-load pattern due to the combined variability of both wind and PV. CSP provides a significant fraction of the net system flexibility to respond to the net demand. 


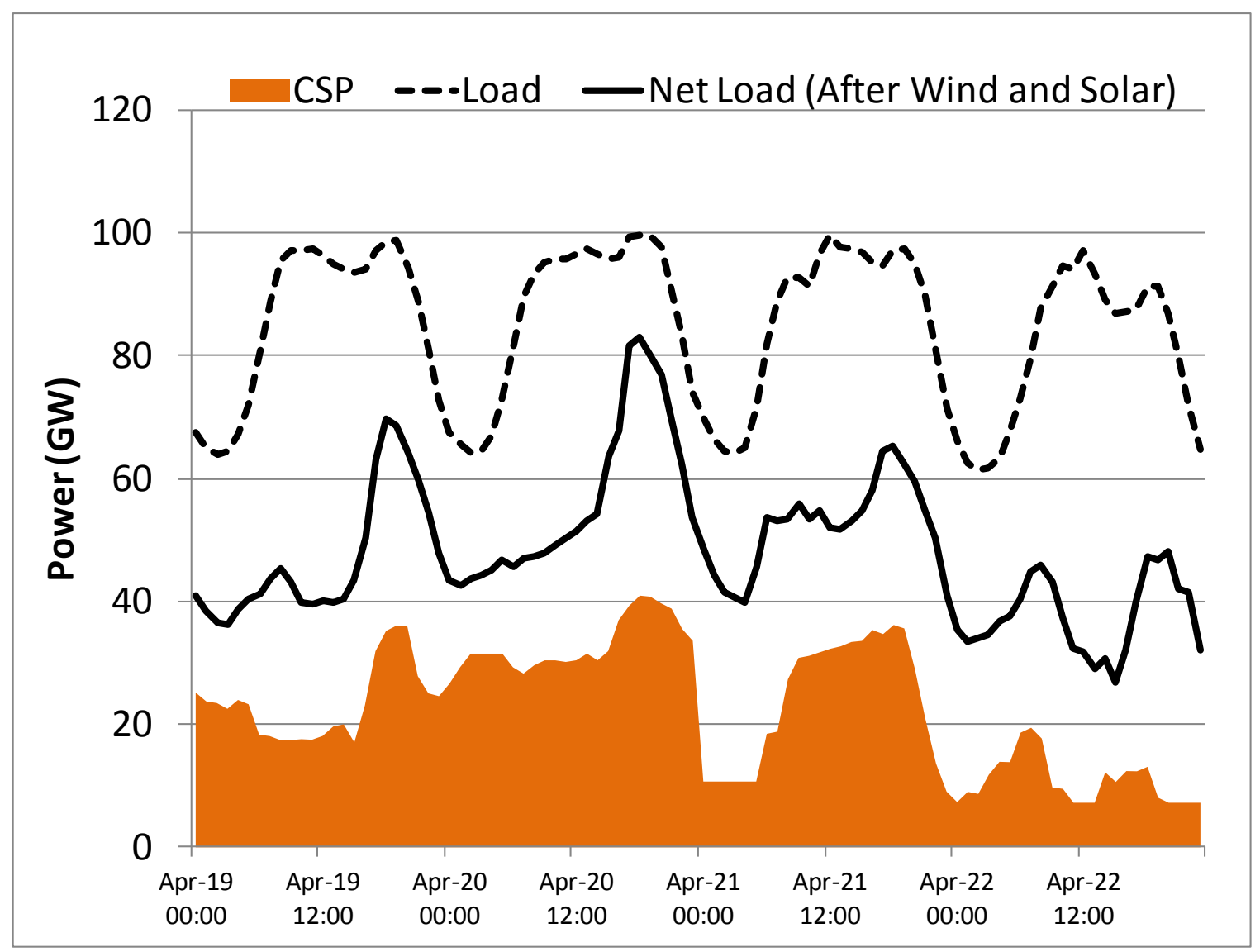

Figure 10. RE Futures 2050 ITI CSP dispatch in the Western Interconnection during four spring days 


\section{Conclusions}

Solar and wind represent the largest renewable resource base in the United States with the technical potential of either technology greatly exceeding the total demand for electricity. However, the variability and uncertainty of these resources requires an increasingly flexible grid at higher penetrations. Recent studies of high penetration renewable scenarios demonstrate the opportunity for the large-scale deployment of CSP with TES to provide a flexible and dispatchable source of energy. These studies find economic opportunities for CSP to provide a significant share of the nation's generation mix. This deployment will likely depend on reduction in the cost of CSP compared to current costs. In all scenarios evaluated, limited CSP deployment is likely to occur at current costs on a pure economic basis.

Achieving even partially the goals of the SunShot Initiative can potentially result in significant deployment. This will depend on two other factors. The first is significant new transmission development. This includes transmission development to connect CSP into the existing grid to supply energy to the southwestern United States and California. Very high penetration will require longer-distance transmission to supply larger areas of the Western Interconnection. Transformational change, where CSP provides $10 \%$ or more of the nation's electricity, will likely require expanded capacity between the Western Interconnection and Eastern Interconnection. The second factor is recognition and valuation of CSP's flexibility and capacity value and consideration of this value during the system planning process. This includes appropriate timing of investment of CSP so its flexibility is available when less-flexible sources of energy are introduced to the grid. Including the value of grid flexibility can produce an overall least-cost energy mix, as opposed to a mix of the lowest-cost energy sources that does not consider the interaction between multiple generation technologies. 


\section{References}

ABB, Inc. (2008). GridView User's Manual, Version 6.0.

Black \& Veatch. (2012). Cost and Performance Data for Power Generation Technologies. Overland Park, KS: Black \& Veatch.

Blair, N. (2007). Concentrating Solar Deployment Systems (CSDS) - A New Model for

Estimating U.S. Concentrating Solar Power Market Potential. NREL Report No. CP-640-41415. Golden, CO: NREL, 2 pp.

Brinkman, G.; Denholm, P.; Drury, E.; Ela, E.; Mai, T.; Margolis, R.; Mowers, M. (2012). Grid Modeling for the SunShot Vision Study. NREL Report No. TP-6A20-53310. Golden, CO: NREL, $38 \mathrm{pp}$.

Denholm, P.; Margolis, R. M. (2007). "Evaluating the Limits of Solar Photovoltaics (PV) in Traditional Electric Power Systems." Energy Policy (35:5); pp. 2852-2861.

Denholm, P.; Margolis, R. M.; Milford, J. M. (2008). "Quantifying Avoided Fuel Use and Emissions from Solar Photovoltaic Generation in the Western United States." Environmental Science and Technology (43:1); pp. 226-232.

Denholm, P.; Drury, E.; Margolis, R. (2009). Solar Deployment System Model (SolarDS): Documentation and Base Case Results. NREL/TP-6A2-45832. Golden, CO: NREL.

Denholm, P.; Mehos, M. (2011). Enabling Greater Penetration of Solar Power via the Use of Thermal Energy Storage. NREL Report No. TP-6A20-52978. Golden, CO: NREL.

EIA. (November 2011). Electric Power Annual 2010. Washington, DC: U.S. Energy Information Administration. Accessed September 18, 2012: http://www.eia.gov/electricity/annual/.

EIA. (2010). Annual Energy Outlook 2010: With Projections to 2035. DOE/EIA-0383(2010). Washington, DC: U.S. Energy Information Administration. Accessed September 18, 2012: http://www.eia.gov/oiaf/aeo/pdf/0383\%282010\%29.pdf.

Madaeni, S.M.; Sioshansi, R.; Denholm, P. (2011). Capacity Value of Concentrating Solar Power Plants. NREL/TP-6A20-51253. Golden, CO: NREL. Accessed September 18, 2012: http://www.nrel.gov/docs/fy11osti/51253.pdf.

Mills, A.; Wiser, R. (June 2012). Changes in the Economic Value of Variable Generation at High Penetration Levels: A Pilot Case Study of California. LBNL-5445E. Berkeley, CA: LBNL.

National Renewable Energy Laboratory. (2012). Renewable Electricity Futures Study. Hand, M.M.; Baldwin, S.; DeMeo, E.; Reilly, J.M.; Mai, T.; Arent, D.; Porro, G.; Meshek, M.; Sandor, D. eds. 4 vols. NREL/TP-6A20-52409. Golden, CO: National Renewable Energy Laboratory.

NREL. (2010). "System Advisor Model (SAM) Version 2010.4.12." Accessed September 18, 2012: https://www.nrel.gov/analysis/sam/. 
Short, W.; Sullivan, P.; Mai, T.; Mowers, M.; Uriarte, C.; Blair, N.; Heimiller, D.; Martinez, A. (2011). Regional Energy Deployment System (ReEDS). NREL/TP-6A20-46534. Golden, CO:

NREL. Accessed September 18, 2012: http://www.nrel.gov/docs/fy12osti/46534.pdf.

U.S. Department of Energy (DOE). (2012). SunShot Vision Study. NREL Report No. BK-520047927; DOE/GO-102012-3037. Washington DC: U.S. Department of Energy. 